\title{
JUKKA KORTTI (2019). MEDIA IN HISTORY: AN INTRODUCTION TO THE MEANINGS AND TRANSFORMATIONS OF COMMUNICATION OVER TIME. LONDON: RED GLOBE PRESS, 248 PP., ISBN: 978-1352005950-0.
}

\section{DOI: 10.51480/1899-5101.13.3(27).10}

Media in History: An Introduction to the Meanings and Transformations of Communication over Time by Jukka Kortti is not just another attempt to be a 'history of media' volume. The author takes a fresh approach and places media into the perspective of human history, instead of vice versa. The prime goal of this method is to provide a counter argument to the 'revolution talk' concerning contemporary media studies. There is an argument that it is a necessity to understand the changes happening nowadays in the fields of media, such as the internet and social media, and in order to do that we should examine their evolution. This perspective may enable us to realize that although the antecedents of the phenomena were claimed to be innovative and novel, they have all existed earlier in the history of mankind.

Jukka Kortti is Adjunct Professor at the University of Helsinki and Aalto University, so an educative spirit is noticeable through the whole text. As mentioned in the Acknowledgments part of the book, the original Finnish version was inspired by the author's own course in media history. The book could be an excellent source for students of various social science fields to understand the basics of media history. Nonetheless, it has more than enough content for seasoned scholars of communication studies, political scientists, historians and researchers of other segments of social sciences. It is also refreshing in regard to its scope. It not only focuses on the USA and western Europe, but also brings examples from other parts of Europe, mainly from Finland. The book besides the Acknowledgments, Introduction and Conclusion is divided into two main parts with each part being segmented into nine chapters, which are divided further into brief subchapters. At the end of some chapters, there are questions and thoughts for further discussions.

The first part of four chapters is titled The Development of Media and provides a chronological historical background for the understanding of the importance of media in history. The first chapter begins with the invention of the alphabet 5000 years ago. The book guides us through the early transformation of oral communication into textual. The author underlines that large-scale written culture could only develop after Gutenberg invented the printing press in the fifteenth 
century. The text follows though the consequent effects of this new technology, such as the growing popularity of printed books, the birth of newspapers and printed media. The second chapter deals with the technological advancements, that brought forth 'new media'. The list includes chronologically the telegraph, the telephone, the phonograph, radio and cinema. The author tries to highlight that ideas of global interconnection appeared with these new tools. For example, Samuel Morse, the inventor of the telegraph envisioned the USA as 'one neighborhood'. The third chapter, titled Media for the Masses explores how the elite nature of these new media advancements flowed down to the general public. Kortti explains how this early form of mass media consumption and production initiated new technological and societal changes, which led to the creation of the 'Global Village' concept by Herbert Marshall McLuhan. The conceptual argument is that thanks to new electronical communication technologies the borders between local and global culture, news and interactions are fading away and every person in the world is living in a 'worldwide village'. Following this logic, chapter four explores the two most important communication devices of the twentieth century: television and the internet.

The second part of the book has five thematic chapters. Media history is analyzed in each chapter from a different perspective. The fifth chapter is titled Media, Democracy and the Public Sphere. The relationship between differing media systems and democracy ideals are explored by providing historical examples of the approaches of several nations. The chapter points out how the development of media and the diverse thinking about democracy correlate with each other. The changes of the public sphere are explored in this chapter from the bourgeois coffeehouses of the eighteenth and nineteenth century to twenty-first century social media platforms. Numerous questions could be asked based on the history of public spheres. Are public spheres of the internet weak, because they separate the people with similar opinions into 'bubbles' or does the web provide opportunities for the creation of new ways for public spheres to operate? The questions are difficult to answer, but the discussion about them is certainly needed. Chapter six, Media, Commerce, and Globalization, is an attempt to show, how media in numerous dimensions of the present is prevalent. Also, this chapter deals with nationalism, globalization and ideas of political economy of communication. Chapter seven, Control and Power: Censorship and Propaganda deals with various censorship and propaganda practices throughout history. The applied methods are constantly changing according to the time and political situation, but they remained prevalent in recent times too. One of the most debated topics of scholars concerns these territories. Censorship of the internet and the new tools of propaganda, such as 'fake news' and 'post-truth politics' are heated topics and Kortti gives us a broader perspective to understand that these phenomena are not without preamble. The eighth chapter, Media and Everyday 
Life describes how media consumption became part of the daily routine and mediatized everyday life. Besides this, it is heavily emphasized that a reverse effect is also prevalent in that the cultural and traditional habits of the consumers altered the production of media. The ninth and last chapter, The Cultural History Meanings of Media raises the question about how media shapes collective historical memory. The growing demand for entertainment urges media producers to use historical stories as a basis. However, these documentary shows, movies or video games are unable to provide the same details that written history studies could and leads to disinformation to a high extent, which is discernible in historical conspiracy theories. Kottri also examines the utopia and dystopia discourse created by the evolving media scene. New technologies are encouraging hopeful voices, as they present them as liberators of mankind, but at same time some claim the opposite. Kottri points out that utopias ever look into an optimistic future, while dystopias are influenced by their times' problems.

The Conclusion repeats the notion that both revolution and evolution viewpoints are prevalent in media history studies. Kottri summarizes how every new advancement in media had to build upon their era's previous economic, sociocultural or technological attributes. This volume is much needed in the ocean of 'revolution' approaches in media studies. The book leaves us to decide, which narrative is closer to the truth, but provides us with more perspective, which was the author's main goal.

László Petrovszki UNIVERSITY OF SZEGED, HUNGARY 